\title{
Non-Neoplastic Brain Disorder
}

National Cancer Institute

\section{Source}

National Cancer Institute. Non-Neoplastic Brain Disorder. NCI Thesaurus. Code C97154.

A non-neoplastic disorder that affects the brain. Representative examples include cerebrovascular disorder, hydrocephalus, and encephalitis. 